\title{
In Vivo Chemical Screening for Modulators of Hematopoiesis and Hematological Diseases
}

\author{
Yiyun Zhang, ${ }^{1,2}$ and J.-R. Joanna Yeh ${ }^{1,2}$ \\ ${ }^{1}$ Cardiovascular Research Center, Massachusetts General Hospital, Charlestown, MA 02129, USA \\ ${ }^{2}$ Department of Medicine, Harvard Medical School, Boston, MA 02115, USA
}

Correspondence should be addressed to J.-R. Joanna Yeh, jyeh1@partners.org

Received 22 February 2012; Accepted 26 April 2012

Academic Editor: Jason Berman

Copyright ( 2012 Y. Zhang and J.-R. J. Yeh. This is an open access article distributed under the Creative Commons Attribution License, which permits unrestricted use, distribution, and reproduction in any medium, provided the original work is properly cited.

\begin{abstract}
In vivo chemical screening is a broadly applicable approach not only for dissecting genetic pathways governing hematopoiesis and hematological diseases, but also for finding critical components in those pathways that may be pharmacologically modulated. Both high-throughput chemical screening and facile detection of blood-cell-related phenotypes are feasible in embryonic/larval zebrafish. Two recent studies utilizing phenotypic chemical screens in zebrafish have identified several compounds that promote hematopoietic stem cell formation and reverse the hematopoietic phenotypes of a leukemia oncogene, respectively. These studies illustrate efficient drug discovery processes in zebrafish and reveal novel biological roles of prostaglandin E2 in hematopoietic and leukemia stem cells. Furthermore, the compounds discovered in zebrafish screens have become promising therapeutic candidates against leukemia and included in a clinical trial for enhancing hematopoietic stem cells during hematopoietic cell transplantation.
\end{abstract}

\section{Introduction}

Zebrafish has been used effectively as a vertebrate model for studying blood cell development and function (for reviews see [1-5]). It is an advantageous model because the optical clarity of its embryos, and their ex utero development enables easy and real-time detection of hematopoietic cells during development. A wide variety of tools and reagents have been developed for in vivo labeling and imaging of blood cells and for investigating blood cell function (for reviews of these methods and protocols, see [6-10]). In addition, transient and stable genetic manipulation can link hematopoietic genes to their functions [11-16]. Added to this arsenal of research tools available in zebrafish is in vivo chemical screening [17-20]. By exposing zebrafish embryos to a chemical library, bioactive compounds that affect any complex developmental and physiological processes may be identified. Furthermore, in vivo chemical screening may be used for uncovering chemical agents that modify a disease phenotype in a whole animal. The compounds that induce a unique biological effect may serve as invaluable probes for identifying critical components of biological pathways, and compounds that can reverse a disease phenotype in vivo may have therapeutic potential or shed light on an effective therapeutic target. This innovative approach has created a unique utility for the zebrafish model in chemical biology and contributed to its emerging role in drug discovery (for additional reviews see [21-24]).

\section{Linking Genes to Their Functions: In Vivo Chemical Screens versus Genetic Screens}

Both genetic and in vivo chemical screens may be used to dissect genetic pathways that regulate specific biological processes. However, an in vivo chemical screen offers the advantage of temporal control that a traditional genetic screen does not. In a genetic screen, gene function is affected from conception. Thus, the role of a gene in early embryonic development may preclude characterization of its roles during later stages. On the other hand, in a chemical screen, compounds that affect the function of a gene can be administered at specific time points and for fixed durations chosen by the investigator so that its roles at different developmental stages may 
be distinctly determined. In addition, in a genetic screen, the roles of a protein family may sometimes be masked by functional redundancy of its family members. However, chemical modulators may exhibit similar activities against multiple members of a protein family and can, therefore, reveal their in vivo cumulative roles. It should be noted that some compounds may affect multiple cellular proteins and thus their on-target effects should be carefully verified using additional chemical agents as well as genetic manipulations. Taken together, in vivo chemical screens may complement traditional genetic approaches and uncover hematopoietic genes that cannot be identified in genetic screens.

\section{Drug Discovery: In Vivo Phenotype-Based Chemical Screening versus Target-Based Approach}

Currently, the most common approach for identifying potential therapeutics is the target-driven approach (for reviews see $[25,26]$ ). This approach relies on a priori understanding of disease mechanisms to the point of knowing a specific cellular component to be targeted. Thereafter, lead compounds may be obtained using in vitro or cell-based assays to determine binding to or modulation of target activity. Typically, these leads will be further optimized using these assays again before being assessed for their in vivo efficacy and toxicity. Targets employed by this approach are often enzymes such as kinases that are likely to have small-molecule binding pockets (for more discussions on target druggability, see reviews $[26,27])$. Proteins that do not have an obvious pocket, such as transcription factors that often act by recruiting other cofactors, are sometimes dubbed undruggable targets.

Target-based chemical screens performed in vitro or in cultured cells are usually very efficient and are able to sample through tens of thousands of compounds. Even so, many drug candidates so identified fail because of poor in vivo potency, intolerable side effects, or inability to demonstrate clinical efficacy (for reviews see [28, 29]). In comparison, chemical screens performed in a whole organism may identify working drugs with a higher rate of success since in vivo potency and toxicity are evaluated simultaneously during the primary screen [30]. Moreover, by design these screens directly identify compounds that have demonstrated their effectiveness of reversing a disease phenotype in vivo. Instead of examining one target as in the target-driven approach, in vivo screening is able to interrogate any potential therapeutic targets existing in a biological system that may mediate a disease phenotype, including targets that act in a non-cell-autonomous manner. In many circumstances, the mechanisms of disease pathology are not fully understood, so a target-driven approach is lacking. In vivo chemical screening, on the contrary, can be performed before a valid molecular target is identified.

Although in vivo screening has a demonstratedly good likelihood of finding efficacious drug candidates, figuring out their mode of action can be a challenge. A significant amount of effort is usually needed to identify the molecular target of the candidate compound. Nevertheless, due to several important advances in analytical research tools including mass spectrometry, proteomics, genomics, metabolomics, expressional profiling, and chemical informatics as well as novel in vivo labeling methods, the efficiency and success rate of target identification have improved significantly in recent years [31-34]. In addition, in vivo chemical screens are sometimes performed using chemical libraries consisting of known bioactive compounds, so that the signaling pathways mediating a disease phenotype can be uncovered relatively quickly once chemical suppressors of the phenotype are identified.

\section{Efficient In Vivo Chemical Screening in Zebrafish}

Some of the model organisms that may be used for in vivo chemical screening are Drosophila, C. elegans and embryonic/larval zebrafish (Danio rerio) (for a review see [35]). All of these models have the scalability required for highthroughput screening. Among them, zebrafish is the only vertebrate model and thus possesses the closest physiological similarities to humans.

Features of zebrafish that enable efficient in vivo chemical screening are multiple. First is their fecundity. One pair of zebrafish can produce 100-200 embryos each week, so even a medium size aquarium with a couple hundred fish can produce thousands to tens of thousands of embryos per week for screening. Second, zebrafish embryos are small. Generally 3-5 embryos can be arrayed in a well of a 96-well plate containing $100-200 \mu \mathrm{L}$ of fish water. Further, most cellpermeable small molecules (with octanol:water partition values, or $\log P$, above zero) can penetrate zebrafish embryos even when they are inside the chorions [36]. Thus, compounds can be added directly into the water surrounding the embryos. For screens performed in 96-well plates at a 10$\mu \mathrm{M}$ concentration, only 1-2 micrograms of each compound will be needed for screening. In addition, zebrafish develop quickly, embryos/larvae at $1-5$ days after fertilization (dpf) already possess various functional physiological systems. The short developmental timeframe significantly condenses the time needed for experimentation. Figure 1 shows a schema of in vivo chemical screening in zebrafish.

The assays employed for in vivo screening will depend on the phenotype of interest. For example, transgenic lines expressing fluorescent proteins under the control of celltype-specific promoters may be used to track the production or location of specific cell types. Thus, zebrafish pu.1, gata1, mpo, lyzC, csf1r, rag2, lck, CD41, or scl reporter lines among others may be used to identify chemical modulators of myeloid cells, erythrocytes, neutrophils, macrophages, $\mathrm{T}$ cells, thrombocytes, or hemangioblasts, respectively [37-45]. Whole-mount immunostaining and RNA in situ hybridization may also be used to detect cell proliferation or expression of cell differentiation markers. Even a wide range of physiological outputs and responses may be used as screening readouts, such as chemical-induced enterocolitis, injuryinduced inflammation, host-pathogen interactions, and laser-induced thrombosis [46-52]. Some of these assays may 

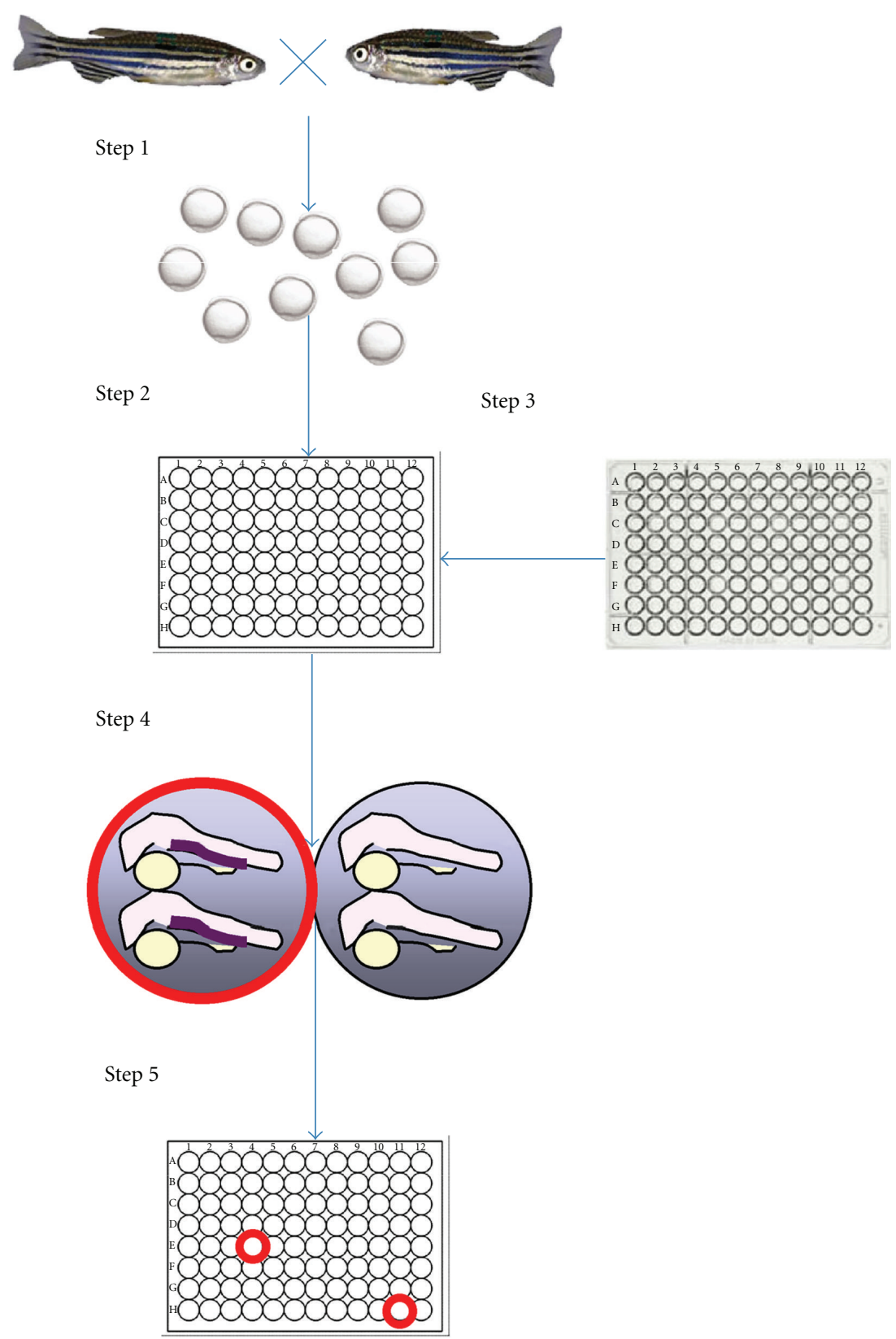

Figure 1: Chemical screening using zebrafish embryos. Step 1-Wild-type, reporter, or mutant zebrafish are crossed to obtain embryos. Step 2-Once reaching an investigator-specified developmental stage (usually between 0-5 days after fertilization), embryos are arrayed into multi-well plates either manually or by automation. Step 3-Compounds from a chemical library are added into the wells containing the embryos using a multichannel pipette or a pin-transfer device. Step 4-After reaching the developmental stage for phenotype manifestation, which is usually within hours to a couple of days after the compound treatment, embryos may be subjected to staining procedures, reporter, or functional assays to detect chemical-induced phenotypes or reversal of genetic phenotypes. The images shown here depict differential hematopoietic gene expression between the compound-treated (red circle) and vehicle-treated (black circle) embryos as detected by RNA in situ hybridization. Step 5-In vivo phenotypes can be detected by visual inspection or by automated imaging and recording. Thus, the whole screening procedure, once optimized, may be automated for high-throughput experimentation and finished within a few days. In addition, a wide range of phenotypes may be detected in vivo.

be processed by automated liquid handling machines or may be recorded using automated imaging systems and analyzed using customized software [51, 53-56]. Thus, conducting chemical screening in zebrafish provides great potential for identifying modulators of hematopoiesis and hematological diseases.

\section{Considerations for Screening Designs, Hit Evaluation, and Translation to Humans}

5.1. Screening Designs. As in any other types of chemical screens, the quality of the hits obtained in zebrafish screens can be directly influenced by the screening designs. 
For example, if a screen is based on the reduction of the signals in a reporter assay, it may be prone to identifying false positives such as toxic compounds. In this case, a quick visual scan of embryo/larva viability before conducting the reporter assay may help exclude those nonspecific hits. In addition, since proper embryonic development depends on precise execution of multiple sequential processes, compounds added at different times will have the opportunity to affect different developmental steps. Thus, the timing and duration of chemical treatment are also likely to affect the screening outcomes. If a screen utilizes a transgenic line, additional validation steps should be incorporated to examine whether the hit compounds may affect the promoter used for driving the transgene or the stability of the transgene itself. For example, in one of the screens that we have performed, we have identified several hits that suppress the heat shock promoter used for driving the expression of an oncogene rather than the activity of the oncogene [20]. Whenever possible, positive controls should be used to validate that zebrafish models exhibit similar molecular machineries and pharmacological responses as humans do (if the screening purpose is drug discovery) for the biological processes under investigation. This confirmation beforehand will facilitate the likelihood of relevantly translating the findings from zebrafish screens to human conditions.

In addition, it is important to conduct a pilot screen using 100 300 compounds and one screening plate of untreated embryos/larvae to evaluate the robustness and potential variables of the screening methods, including the degrees of natural variations among different clutches of embryos/larvae. A pilot screen may also provide information as regard to the potential hit rates. On one hand, in vivo screening methods may cast a broad net for identifying compounds that elicit the phenotype-of-interest through various mechanisms. On the other hand, if the hit rates are higher than $1-2 \%$, researchers may wish to incorporate secondary screening strategies or consider a different screening method in order to limit the hits to the ones that are likely to be of potential interest to the investigators. For example, we previously showed that immediately after the expression of the leukemia oncogene AML1-ETO, gatal expression is abolished, whereas myeloperoxidase (mpo) expression is increased at a later time point [57]. We conducted a chemical suppressor screen and identified various compounds that can restore gatal expression in the presence of AML1-ETO [20]. We have also verified the therapeutic potential of some of the hits identified in this screen, and these results will be discussed in more detail later. Conceivably, a chemical suppressor screen can also be performed based on the reversal of mpo upregulation in the same zebrafish model. The latter screening strategy may not only identify compounds that directly antagonize AML1-ETO's effects but also additional compounds that suppress the accumulation of $m p o^{+}$cells through AML1-ETO-unrelated mechanisms. The choices of screening designs are subject to each investigator's discretion.

5.2. Hit Evaluation and Translation to Humans. The potency, effectiveness, and specificity of the confirmed hits obtained from zebrafish screens have already been demonstrated in vivo. Thus, these hits have a high probability of being effective in other in vivo systems. Both hematopoietic and other nonhematopoietic effects of these candidate compounds should be evaluated further in embryonic/larval zebrafish. The effects of the candidate compounds on cell differentiation, proliferation, or survival can be evaluated using whole-mount RNA in situ hybridization, whole-mount immunostaining or staining with lineage-specific cytological dyes such as Sudan Black for neutrophils and o-dianisidine for hemoglobin. These in vivo effects may be assessed facilely using embryonic/larval zebrafish. For example, we have found that AML1-ETO can reprogram hematopoietic cell fate decisions, converting the erythroid cell fate to the granulocytic cell fate. We have also found that nimesulide, a chemical suppressor of AML1-ETO, can reverse these effects in zebrafish. AML1-ETO has been shown to suppress erythroid differentiation in mammalian cells, and we have confirmed that nimesulide can also reverse AML1-ETO's effects in cultured cells [20]. The effects of candidate compounds on leukocyte or thrombocyte function can also be assessed in embryonic/larval zebrafish using an injury model for neutrophil chemotaxis, a bacterial infection model for phagocytosis, or a laser-induced coagulation assay [47, 58, 59]. Moreover, lineage-specific hematopoietic cells can be isolated from control and compound-treated embryos/larvae of various fluorescent reporter lines mentioned earlier by flow cytometry for transcriptional profiling analysis. Interestingly, the nonhematopoietic effects may sometimes provide instrumental information as to the mechanisms of action of the candidate compounds. For example, a candidate compound may cause a developmental phenotype similar to the phenotype caused by other genetic mutations or other chemicals with known bioactivities, suggesting that the candidate compound acts through a similar pathway as these other modulations do. The effects of the candidate compounds can also be evaluated in adult zebrafish using standard hematopoietic assays adapted from mouse models, including irradiation followed by hematopoietic cell transplantation and irradiation recovery assays, as well as leukemic cell xenograft and limiting dilution transplantation [37, 60-64]. The zebrafish provides the investigator the flexibility at which point to verify the effects of these compounds in mammalian systems. While the degree of conservation between zebrafish and mammals in hematopoiesis and in the functions of many hematopoietic cell lineages is high, conservation of humoral regulators and the adaptive immune system is presently less clear. However, rapid advancement in those areas is anticipated. For those biological processes already shown to be highly conserved, the translatability of the screening hits from zebrafish to humans will likely to be high.

\section{Zebrafish Hematopoiesis and Hematological Disease Models in Zebrafish}

6.1. Hematopoiesis. Zebrafish possesses a similar set of blood lineages as the mammals $[11,14,63,65-71]$. The genes involved in blood cell development are also highly conserved 
between zebrafish and mammals $[72,73]$. Thus, it is a suitable model for investigating the genetic pathways regulating hematopoiesis and hematological diseases.

As in mammals, during embryonic development, zebrafish first exhibit a primitive wave of hematopoiesis and later produce several intermediate cell types that eventually contribute to definitive hematopoiesis (for more detailed reviews see $[74,75])$. During primitive hematopoiesis, which begins around 11 hours after fertilization (hpf), zebrafish embryos produce myeloid and erythroid cells in two anatomically separate locations. Myeloid cells, which express the transcription factor pu.1, are formed in the anterior lateral plate mesoderm (ALM), while erythroid progenitors expressing the gatal transcription factor are formed in the posterior lateral plate mesoderm (PLM). It has been shown that hematopoietic cell fate in both blood islands is determined by the expression of these two genes. While knockdown of pu. 1 induces erythropoiesis in the ALM, knockdown of gata 1 promotes myelopoiesis in the PLM [76, 77]. These results indicate that primitive hematopoiesis in embryonic zebrafish produces bi-potent hematopoietic progenitor cells. Thus, these two synchronously specified blood populations may be useful for identifying important genes that regulate myeloid and erythroid cell fate determination. In a later section of this paper, we will discuss a study that utilizes these cells to uncover some of the AML1-ETO's oncogenic effects that lead to acute myeloid leukemia [20,57].

In zebrafish, multipotent hematopoietic stem cells (HSCs) originate in the hemogenic endothelium of the aorta, which is equivalent to the aorta-gonad-mesonephros (AGM) in mammals [78]. Using in vivo lineage-tracing experiments, it has been shown that these newly emerged HSCs will subsequently colonize a transient hematopoietic tissue called the caudal hematopoietic tissue (CHT), which may be comparable to another mammalian embryonic hematopoietic site in the fetal liver [79-81]. Finally, HSCs from those regions will migrate to and seed both kidney (equivalent to bone marrow in mammals) and thymus, the final hematopoietic organs that remain through adult life [79-81]. As in mammals, zebrafish HSCs express runxl and cmyb, and runxl deficiency abrogates definitive hematopoiesis in fish [78, 82-84]. Several major signaling pathways that regulate HSC formation and homeostasis in mouse models also affect HSC formation in zebrafish, such as the Hedgehog (Hh) pathway and the Notch-Runx pathway $[78,85]$. Recently, an in vivo chemical screen in zebrafish has identified important roles of the prostaglandin-E2-(PGE2-) Wnt signaling pathway in HSC formation $[19,86]$, which will be discussed in more detail later. These findings suggest that zebrafish and mammals utilize similar genetic circuitry for regulating HSC formation.

6.2. Hematological Disease Models. Due to the easiness of inspecting blood cell phenotypes in zebrafish embryos, a large number of blood mutants have been isolated in three large-scale genetic screens $[11,14,87,88]$. Many of these blood mutants have defects in the maturation or iron transport of erythrocytes, and their related phenotypes and orthologous gene mutations have been defined in humans
[89-91]. Transgenesis approaches have also been used to create various hematological disease models in zebrafish, of which the majority are blood cancer models [20, 38, 57, 9296]. In these studies, ectopic expression of human oncogenes resulted in zebrafish phenotypes reminiscent of human leukemia characteristics. In addition, investigators can now perform efficient targeted gene disruption in zebrafish using engineered zinc finger nucleases (ZFNs) and transcription activator-like effector (TALE) nucleases [13, 16, 97-100]. In the future, many of these hematological disease models may be used for chemical suppressor screens. The vast array of research tools available in the zebrafish model combined with in vivo chemical screening will prove useful in providing novel insights into the molecular mechanisms and potential therapy for hematological diseases.

\section{In Vivo Identification of Hematopoietic Stem Cell (HSC) Chemical Modulators}

Compounds that can augment HSC formation and function may exert therapeutic benefits to patients undergoing hematopoietic cell transplantation. North et al. performed a chemical screen to identify small molecules regulating HSC formation in zebrafish embryos [19]. In this study, embryos were exposed between 11 and $36 \mathrm{hpf}$ to 2,357 compounds from three chemical libraries of known bioactive compounds. As mentioned above, HSCs are $\mathrm{cmyb}^{+}$and runx $1^{+}$ and both transcription factors are indispensable for HSC development. By examining cmyb and runxl expression using RNA in situ hybridization, the authors found $35 \mathrm{com}$ pounds that increased HSC numbers and another 47 compounds that decreased them. Based on their known bioactivities, they found that 10 of these compounds affect prostanoid biosynthesis. Prostanoids, including prostaglandins, prostacyclins, and thromboxanes, are lipid mediators that play major roles in inflammation and other physiological responses. The cyclooxygenases (COXs), including COX-1 and COX-2 (also known as prostaglandin G/H synthase 1 and 2 ), convert arachidonic acid into prostaglandin $\mathrm{H} 2$, which can then be metabolized into other prostanoids by additional enzymes [101]. Interestingly, the authors found that while exposure to COX inhibitors such as celecoxib and sulindac reduced cmyb/runxl expression in the hemogenic aorta, exposure to linoleic acid, a precursor of arachidonic acid, enhanced it. Previously it had been shown that prostaglandin E2 (PGE2) is the major prostanoid produced in zebrafish embryos [102]. Thus, North et al. confirmed the involvement of the prostaglandin pathway in HSC formation by incubating zebrafish embryos with PGE2 or selective inhibitors of COX-1 and COX-2, as well as by genetic knockdown of $p t g s 1$ and ptgs 2 that encode COX-1 and COX-2 proteins, respectively. Subsequently, the authors investigated the expression patterns of ptgs 1 and ptgs 2 and found that both genes were upregulated at the onset of definitive hematopoiesis. While both genes were expressed in the HSCs, ptgs1 was also expressed in the neighboring endothelium. These results strongly suggest that COX-1 and COX-2 promote HSC formation through functions in both the HSCs and their 
niche. Furthermore, Goessling et al. showed that PGE2 promotes HSC formation by activating the $\mathrm{Wnt} / \beta$-catenin signaling pathway [86].

In their screen, North et al. also found 22 compounds that might regulate HSC formation through their effects on blood flow, such as compounds affecting $\alpha$ - and $\beta$-adrenergic receptors, $\mathrm{Ca}^{2+}$ or $\mathrm{Na}^{+} / \mathrm{K}^{+}$channels, nitric oxide (NO) synthesis, or the angiotensin pathway [103]. They showed that blood flow had a positive impact on cmyb/runxl expression, suggesting that the hemodynamic force on the endothelium might be an inducing factor for the emergence of HSCs. In addition, the authors found that NO donors could stimulate HSC formation even in the silent heart mutant, which does not exhibit blood flow. Using mosaic transplantation experiments, they discovered that $\mathrm{NO}$ positively regulated HSC through cell-autonomous signaling.

\section{Validation of HSC Chemical Modulators and Their Clinical Potential}

Hematopoietic cell transplantation (HCT) is frequently used in the treatment of hematological malignancies. HSCs not only self-renew but also give rise to all blood lineages and can repopulate an entire hematopoietic system. Patients about to receive HCT need to undergo myeloablation and are treated simultaneously with immunosuppressants to prevent transplant rejection. It is essential that the transplanted HSCs effectively and efficiently engraft in the bone marrow. Various methods aiming to enhance the in vitro and in vivo expansion of stem/progenitor cells and their homing efficiency to bone marrow are currently under intensive investigation [104-107]. The chemical modulators of HSCs identified by North et al. in zebrafish represent another new therapeutic opportunity.

North et al. showed that ex vivo exposure of mouse whole bone marrow (WBM) or purified lin $^{-} \mathrm{Scal}^{+} \mathrm{c}-\mathrm{Kit}^{+}$(LSK) cells to dimethyl-prostaglandin E2 (dmPGE2), a long-lasting derivative of PGE2, significantly increased the progenitor cell numbers as measured by spleen colony-forming units at day 12 after transplantation (CFU-S12) in the recipient mice. Using a limiting dilution competitive repopulation analysis, they found that dmPGE2-treated WBM resulted in 4- and 2.3-fold increases of HSCs in the recipients compared to the untreated cells at 12 and 24 weeks, respectively, following the transplants [19]. To define the mechanisms of action of PGE2, Hoggatt et al. showed that ex vivo exposure to PGE2 promoted HSC homing efficiency, proliferation, and survival during engraftment [108].

Clinically, sources for HCT include bone marrow, mobilized peripheral blood stem cells (MPBSCs), or human cord blood (hCB). Approximately 20\% of HCTs in the United States are conducted using hCB [109]. However, recovery after hCB transplant often takes a very long time due to the limited volume of its source. Thus, Goessling et al. went on to show that dmPGE2 could enhance hCB hematopoietic colony formation in vitro and its engraftment in xenotransplantation [110]. Interestingly, the authors found that hCB samples treated with dmPGE2 exhibited gene expression patterns reminiscent of the HSCs emerged from a vascular niche [110]. Since hCB contains both HSCs and endothelial cells, the authors postulated that dmPGE2 might promote HSC formation from hemogenic endothelial cells, analogous to the scenario in developing zebrafish embryos. Alternatively, Butler et al. have shown that endothelial cells can provide signals for retaining HSC multipotency [111]. Finally, Goessling et al. provided evidence demonstrating preclinical safety of their regimen in nonhuman primate autologous transplantation [110]. Thus, from its initial discovery using an in vivo chemical screen in zebrafish, PGE2 is now entering a Phase I clinical trial.

\section{In Vivo Identification of Acute Myelogenous Leukemia (AML) Chemical Suppressors}

9.1. AML1-ETO and the t(8;21) AML. Our lab has conducted an in vivo chemical screen to identify compounds that could reverse the hematopoietic phenotypes of a human leukemia oncogene [20]. AML1-ETO is a fusion gene resulting from $\mathrm{t}(8 ; 21)(\mathrm{q} 21 ; \mathrm{q} 22)$ chromosomal translocation, and it is one of the most common translocation products in AML. In particular, AML1-ETO expression accounts for $40 \%$ of AML in the FAB (French-American-British) M2 subtype [112]. These patients can be characterized by overabundance of granulocytic blast cells.

AML-1, also known as Runx-1, is one of two subunits that form a heterodimeric transcription factor called the core binding factor $(\mathrm{CBF})$. The $\mathrm{CBF}$ plays many important roles in hematopoiesis by regulating hematopoietic gene expression (for review see [113]). It has been shown that AML1ETO exerts a dominant-negative effect on CBF function; however, recent studies also suggest that it produces other gain-of-function effects that account for its oncogenicity [114]. Expression of AML1-ETO enhances HSC expansion both in vitro and in vivo and promotes myelopoiesis while blocking myeloid maturation [115-119]. Despite intensive studies on gene regulation mediated by AML-ETO, to date no effective therapeutic target has been validated in vivo. Thus, we postulated that a phenotype-based, nonbiased approach such as in vivo chemical screening might uncover potential therapeutics and identify the critical downstream effectors of AML-ETO.

9.2. A Zebrafish Model for AML1-ETO Leukemia. A transgenic zebrafish line $\operatorname{Tg}(h s p: A M L 1-E T O)$ was established to enable heat-inducible expression of human AML1-ETO [57]. It was found that expression of AML1-ETO in embryonic zebrafish resulted in an accumulation of hematopoietic cells in the posterior blood island $[57,120]$. Cytological analysis of the hematopoietic cells isolated from the transgenic embryos showed plentiful immature cells seldom seen in the control samples. In addition, genome-wide expression analysis identified various important similarities between the hematopoietic cells of the transgenic zebrafish and human $t(8 ; 21)$ leukemia cells [57]. Previously it had been shown that AML1ETO suppresses erythroid differentiation in human multipotent hematopoietic cells [121]. In the zebrafish model, it was found that AML1-ETO caused the downregulation of gata1 
and the upregulation of pu.1 in multipotent hematopoietic progenitors, suggesting a conversion of erythroid to myeloid cell fate. Moreover, the accumulated hematopoietic cells strongly expressed the myeloperoxidase (mpo) gene, indicative of a granulocytic cell fate. A previous study had shown that AML1-ETO downregulates c/ebp $\alpha$, resulting in a maturation block of the granulocytic cells in human $t(8 ; 21)$ AML [122]. In the zebrafish model, we also observed a dramatic reduction of c/ebp $\alpha$ expression, suggesting that only two days after its expression in zebrafish embryos, AML1ETO induced an accumulation of granulocytic blast cells resembling the clinical features of human $\mathrm{t}(8 ; 21)$ AML.

9.3. Chemical Screening in the Zebrafish Model of AML-ETO. A library of 2,000 bioactive compounds was screened using the $\operatorname{Tg}(h s p: A M L 1-E T O)$ zebrafish model [20]. The screening compounds were added to embryos at 12-16 hpf, followed by 1 hour of heat treatment to induce AML1-ETO expression. Fifteen hit compounds were identified by restored gatal expression in the transgenic embryos as measured by RNA in situ hybridization. We found that some of the compounds affected the heat shock response in zebrafish, preventing AML1-ETO expression. In addition, we identified a histone deacetylase (HDAC) inhibitor sodium valproate as a chemical suppressor of AML1-ETO's effects. HDAC is a transcription corepressor that is known to interact with the ETO moiety of the AML1-ETO protein [123]. It has been shown that recruitment of HDAC is critical for AE's function, and that an HDAC inhibitor trichostatin A (TSA) induces differentiation and apoptosis of a $t(8 ; 21)$ AML cell line [124]. We have shown previously that TSA also reversed the hematopoietic phenotype of $\operatorname{Tg}(h s p: A M L 1-E T O)$ zebrafish [57]; therefore, the discovery of sodium valproate validated the biological relevance of the chemical screen performed on the AML1-ETO zebrafish model.

Interestingly, nimesulide, a selective COX-2 inhibitor, was also identified in this screen [20]. Subsequently, we showed that treatments with indomethacin (a nonselective COX inhibitor), NS-398 (a selective COX-2 inhibitor), and nimesulide not only restored gatal expression but also inhibited increased expression of mpo in the transgenic embryos. Furthermore, we demonstrated that these drugs' effects were on target because they could be reversed by supplementing a downstream metabolite PGE2. Thus, the hematopoietic differentiation defects induced by AML1-ETO in vivo can be rescued by inhibiting the COX enzymes.

\section{Validation of AML Chemical Suppressors and Their Clinical Potential}

Since COX inhibitors scored as hits in our screen, we investigated the genes coding for COX proteins and found that ptgs2 but not $p$ tgs 1 expression was significantly upregulated in the hematopoietic cells of $\operatorname{Tg}(h s p: A M L 1-E T O)$ zebrafish [20]. At the time of this discovery, very little was known about the potential contribution of the COX enzymes in AML leukemogenesis, although overexpression of COX-2 had been reported in various types of epithelial tumors, including colorectal carcinoma and breast cancers $[125,126]$. Moreover, PGE2 had been shown to promote colon cancer cell growth via a $\beta$-catenin-dependent signaling pathway [127, 128]. As in zebrafish, we found that AML1-ETO induced ptgs 2 but not ptgs1 expression in the K562 human myeloid leukemia cell line [20]. AML1-ETO induced the activity of a $\beta$-catenin reporter and inhibited erythroid differentiation in these cells, and both effects could be abrogated by NS398. Subsequently, we found that genetic knockdown of $\beta$ catenin rescued AML1-ETO's effects in zebrafish embryos [20]. Thus, AML1-ETO affects hematopoietic differentiation through the COX-2/ $\beta$-catenin pathway in both zebrafish and human leukemia cells.

Since the publication of these findings, we have obtained strong evidence indicating that AML1-ETO also signals through a COX-2/ $\beta$-catenin pathway in mouse bone marrow cells (Zhang et al., unpublished results). We have found that COX inhibitors can effectively suppress in vitro serial replating of hematopoietic stem/progenitor cells expressing AML1-ETO as well as AML1-ETO-mediated tumorigenesis in various in vivo mouse models (Zhang et al., unpublished results). Two recent studies have also explored the roles of the COX enzymes and $\beta$-catenin in leukemia stem cells expressing other leukemia oncogenes $[129,130]$. In one of the studies, Wang et al. showed that either the MLL-AF9 fusion oncoprotein or coexpression of Hoxa9 and Meis1a could induce ptgs1 expression and $\beta$-catenin activation. In addition, inhibiting COX activities using indomethacin attenuated leukemia development induced by MLL-AF9 or by coexpression of Hoxa9 and Meisla oncogenes [129]. In the other study, Steinert et al. found that a nonselective COX inhibitor sulindac prevented $\beta$-catenin from being activated and reduced in vivo growth of HSCs expressing PML/RAR $\alpha$ or PLZF/RAR $\alpha$ oncogenes [130].

Collectively, these results suggest that inhibiting the COX enzymes using nonsteroidal anti-inflammatory drugs (NSAIDs) can suppress oncogenic function and $\beta$-catenin activation in AML leukemia stem cells. Interestingly, casebased studies have also suggested an inverse relationship between NSAID usage and AML incidence [131, 132]. Although PGE2 can induce $\beta$-catenin expression and augment some aspects of HSC function as discussed above, it has been shown that loss of $\beta$-catenin does not affect normal hematopoiesis in adult mice [133-136]. At present, a major obstacle for achieving long-term survival of AML patients is relapse. Although chemotherapy can effectively induce remission in the majority of patients, more than $50 \%$ of the patients experience relapse within a year after remission $[137,138]$. In sum, these results suggest that NSAIDs may impair leukemia stem cell function and thus their clinical efficacy in preventing AML relapse should be explored.

\section{Final Considerations for Drug Discovery in Zebrafish}

In this paper, we presented two specific studies on hematopoiesis that appropriately exemplify the general utility of embryonic zebrafish and phenotypic in vivo chemical 
screening in discovering potential new therapeutics. In these cases, the use of an in vivo screening platform allowed the identification of compounds that may act in a noncell autonomous fashion such as hemodynamic forces, bypassed the well-known technical difficulties involved in culturing hematopoietic or leukemia stem cells, and also circumvented the obstacles conferred by undruggable targets or unknown disease mechanisms. Both of the studies uncovered novel biological mechanisms as well as strong candidates for clinical therapeutic use. It is important to note that most of the advantageous features of the zebrafish model occur at its embryonic and larval stages. Thus, a disease phenotype under investigation must manifest during these stages in order to be most effectively exploited for chemical screening. Since multitudinous signaling pathways acting together in zebrafish during early development are also likely to play important roles in maintaining homeostasis in adults and may be disrupted or reactivated during disease progression, a surrogate embryonic phenotype can often be very useful for identifying potential disease modulators. For example, compounds that suppress T-cell development in embryonic zebrafish may demonstrate potent inhibitory effects against T-cell leukemia [18]. Overall, drug discovery in zebrafish benefits from the feasibility of high-throughput chemical screening, closer physiological similarities to human than invertebrate screening strategies, and the ability to create complex disease models not achievable in vitro. The possibility of detecting a wider range of hematopoietic phenotypes using innovative assays promises an ever-increasing role for zebrafish in future drug discovery processes.

\section{Conflict of Interests}

The authors declare no competing financial interests.

\section{Acknowledgments}

The authors thank Taneli Helenius, Caroline Burns, and Randall Peterson for helpful comments on the paper. Funding for this work was provided by U.S. National Institutes of Health Grants R01 CA140188 (J.-R. J. Yeh), K01 AG031300 (J.-R. J. Yeh) and Massachusetts General Hospital Claflin Distinguished Scholar Award (J.-R. J. Yeh).

\section{References}

[1] S. A. Renshaw and N. S. Trede, "A model 450 million years in the making: zebrafish and vertebrate immunity," Disease Models and Mechanisms, vol. 5, no. 1, pp. 38-47, 2012.

[2] E. Payne and T. Look, "Zebrafish modelling of leukaemias," British Journal of Haematology, vol. 146, no. 3, pp. 247-256, 2009.

[3] J. Y. Bertrand and D. Traver, "Hematopoietic cell development in the zebrafish embryo," Current Opinion in Hematology, vol. 16, no. 4, pp. 243-248, 2009.

[4] F. Ellett and G. J. Lieschke, "Zebrafish as a model for vertebrate hematopoiesis," Current Opinion in Pharmacology, vol. 10, no. 5, pp. 563-570, 2010.
[5] L. Jingd and L. I. Zon, "Zebrafish as a model for normal and malignant hematopoiesis," Disease Models and Mechanisms, vol. 4, no. 4, pp. 433-438, 2011.

[6] C. Hall, M. V. Flores, K. Crosier, and P. Crosier, "Live cell imaging of zebrafish leukocytes," Methods in Molecular Biology, vol. 546, pp. 255-271, 2009.

[7] P. Jagadeeswaran, M. Carrillo, U. P. Radhakrishnan, S. K. Rajpurohit, and S. Kim, "Laser-induced thrombosis in zebrafish," Methods in Cell Biology, vol. 101, pp. 197-203, 2011.

[8] P. Li and L. I. Zon, "Stem cell migration: a zebrafish model," Methods in Molecular Biology, vol. 750, pp. 157-168, 2011.

[9] D. L. Stachura and D. Traver, "Cellular dissection of zebrafish hematopoiesis," Methods in Cell Biology, vol. 101, pp. 75-110, 2011.

[10] A. M. Taylor and L. I. Zon, "Zebrafish tumor assays: the state of transplantation," Zebrafish, vol. 6, no. 4, pp. 339-346, 2009.

[11] B. M. Weinstein, A. F. Schier, S. Abdelilah et al., "Hematopoietic mutations in the zebrafish," Development, vol. 123, pp. 303-309, 1996.

[12] J. D. Sander, J.-R. J. Yeh, R. T. Peterson, and J. K. Joung, "Engineering zinc finger nucleases for targeted mutagenesis of zebrafish," Methods in Cell Biology, vol. 104, pp. 51-58, 2011.

[13] J. D. Sander, L. Cade, C. Khayter et al., "Targeted gene disruption in somatic zebrafish cells using engineered TALENs," Nature Biotechnology, vol. 29, no. 8, pp. 697-698, 2011.

[14] D. G. Ransom, P. Haffter, J. Odenthal et al., "Characterization of zebrafish mutants with defects in embryonic hematopoiesis," Development, vol. 123, pp. 311-319, 1996.

[15] A. Nasevicius and S. C. Ekker, "Effective targeted gene "knockdown" in zebrafish," Nature Genetics, vol. 26, no. 2, pp. 216-220, 2000.

[16] P. Huang, A. Xiao, M. Zhou, Z. Zhu, S. Lin, and B. Zhang, "Heritable gene targeting in zebrafish using customized TALENs," Nature Biotechnology, vol. 29, no. 8, pp. 699-700, 2011.

[17] M. F. Cusick, J. E. Libbey, N. S. Trede, D. D. Eckels, and R. S. Fujinami, "Human T cell expansion and experimental autoimmune encephalomyelitis inhibited by Lenaldekar, a small molecule discovered in a zebrafish screen," Journal of Neuroimmunology, vol. 244, no. 1-2, pp. 35-44, 2012.

[18] S. Ridges, W.L. Heaton, D. Joshi et al., "Zebrafish screen identifies novel compound with selective toxicity against leukemia," Blood. In press.

[19] T. E. North, W. Goessling, C. R. Walkley et al., "Prostaglandin E2 regulates vertebrate haematopoietic stem cell homeostasis," Nature, vol. 447, no. 7147, pp. 1007-1011, 2007.

[20] J. R. J. Yeh, K. M. Munson, K. E. Elagib, A. N. Goldfarb, D. A. Sweetser, and R. T. Peterson, "Discovering chemical modifiers of oncogene-regulated hematopoietic differentiation," Nature Chemical Biology, vol. 5, no. 4, pp. 236-243, 2009.

[21] I. T. Helenius and J. R. Yeh, "Small zebrafish in a big chemical pond," Journal of Cellular Biochemistry, vol. 113, no. 7, pp. 2208-2216, 2012.

[22] D. Kokel and R. T. Peterson, "Chemobehavioural phenomics and behaviour-based psychiatric drug discovery in the zebrafish," Briefings in Functional Genomics and Proteomics, vol. 7, no. 6, pp. 483-490, 2008.

[23] P. J. Schlueter and R. T. Peterson, "Systematizing serendipity for cardiovascular drug discovery," Circulation, vol. 120, no. 3, pp. 255-263, 2009. 
[24] L. I. Zon and R. T. Peterson, "In vivo drug discovery in the zebrafish," Nature Reviews Drug Discovery, vol. 4, no. 1, pp. 35-44, 2005.

[25] M. A. Lindsay, "Target discovery," Nature Reviews Drug Discovery, vol. 2, no. 10, pp. 831-838, 2003.

[26] A. L. Hopkins and C. R. Groom, "The druggable genome," Nature Reviews Drug Discovery, vol. 1, no. 9, pp. 727-730, 2002.

[27] T. H. Keller, A. Pichota, and Z. Yin, "A practical view of "druggability"," Current Opinion in Chemical Biology, vol. 10, no. 4, pp. 357-361, 2006.

[28] S. M. Paul, D. S. Mytelka, C. T. Dunwiddie et al., "How to improve RD productivity: the pharmaceutical industry's grand challenge," Nature Reviews Drug Discovery, vol. 9, no. 3, pp. 203-214, 2010.

[29] B. Munos, "Lessons from 60 years of pharmaceutical innovation," Nature Reviews Drug Discovery, vol. 8, no. 12, pp. 959-968, 2009.

[30] D. C. Swinney and J. Anthony, "How were new medicines discovered?" Nature Reviews Drug Discovery, vol. 10, no. 7, pp. 507-519, 2011.

[31] S. E. Ong, B. Blagoev, I. Kratchmarova et al., "Stable isotope labeling by amino acids in cell culture, SILAC, as a simple and accurate approach to expression proteomics," Molecular \& Cellular Proteomics, vol. 1, no. 5, pp. 376-386, 2002.

[32] C. Laggner, D. Kokel, V. Setola et al., "Chemical informatics and target identification in a zebrafish phenotypic screen," Nature Chemical Biology, vol. 8, no. 2, pp. 144-146, 2012.

[33] P. L. Ross, Y. N. Huang, J. N. Marchese et al., "Multiplexed protein quantitation in Saccharomyces cerevisiae using amine-reactive isobaric tagging reagents," Molecular and Cellular Proteomics, vol. 3, no. 12, pp. 1154-1169, 2004.

[34] A. Westman-Brinkmalm, A. Abramsson, J. Pannee et al., "SILAC zebrafish for quantitative analysis of protein turnover and tissue regeneration," Journal of Proteomics, vol. 75, pp. 425-434, 2011.

[35] J. Giacomotto and L. Ségalat, "High-throughput screening and small animal models, where are we?" British Journal of Pharmacology, vol. 160, no. 2, pp. 204-216, 2010.

[36] C. Sachidanandan, J. R. J. Yeh, Q. P. Peterson, and R. T. Peterson, "Identification of a novel retinoid by small molecule screening with zebrafish embryos," PLoS One, vol. 3, no. 4, Article ID e1947, 2008.

[37] D. M. Langenau, A. A. Ferrando, D. Traver et al., "In vivo tracking of T cell development, ablation, and engraftment in transgenic zebrafish," Proceedings of the National Academy of Sciences of the United States of America, vol. 101, no. 19, pp. 7369-7374, 2004.

[38] D. M. Langenau, D. Traver, A. A. Ferrando et al., "Mycinduced T cell leukemia in transgenic zebrafish," Science, vol. 299, no. 5608, pp. 887-890, 2003.

[39] K. Hsu, D. Traver, J. L. Kutok et al., "The pu.1 promoter drives myeloid gene expression in zebrafish," Blood, vol. 104, no. 5, pp. 1291-1297, 2004.

[40] H. F. Lin, D. Traver, H. Zhu et al., "Analysis of thrombocyte development in CD41-GFP transgenic zebrafish," Blood, vol. 106, no. 12, pp. 3803-3810, 2005.

[41] X. Y. Zhang and A. R. F. Rodaway, "SCL-GFP transgenic zebrafish: in vivo imaging of blood and endothelial development and identification of the initial site of definitive hematopoiesis," Developmental Biology, vol. 307, no. 2, pp. 179-194, 2007.

[42] Q. Long, A. Meng, M. Wang, J. R. Jessen, M. J. Farrell, and S. Lin, "GATA-1 expression pattern can be recapitulated in living transgenic zebrafish using GFP reporter gene," Development, vol. 124, no. 20, pp. 4105-4111, 1997.

[43] C. Hall, M. Flores, T. Storm, K. Crosier, and P. Crosier, "The zebrafish lysozyme C promoter drives myeloid-specific expression in transgenic fish," BMC Developmental Biology, vol. 7, article no. 42, 2007.

[44] C. Gray, C. A. Loynes, M. K. B. Whyte, D. C. Crossman, S. A. Renshaw, and T. J. A. Chico, "Simultaneous intravital imaging of macrophage and neutrophil behaviour during inflammation using a novel transgenic zebrafish," Thrombosis and Haemostasis, vol. 105, no. 5, pp. 811-819, 2011.

[45] J. R. Mathias, B. J. Perrin, T. X. Liu, J. Kanki, A. T. Look, and A. Huttenlocher, "Resolution of inflammation by retrograde chemotaxis of neutrophils in transgenic zebrafish," Journal of Leukocyte Biology, vol. 80, no. 6, pp. 1281-1288, 2006.

[46] S. H. Oehlers, M. V. Flores, K. S. Okuda, C. J. Hall, K. E. Crosier, and P. S. Crosier, "A chemical enterocolitis model in zebrafish larvae that is dependent on microbiota and responsive to pharmacological agents," Developmental Dynamics, vol. 240, no. 1, pp. 288-298, 2011.

[47] B. Thattaliyath, M. Cykowski, and P. Jagadeeswaran, "Young thrombocytes initiate the formation of arterial thrombi in zebrafish," Blood, vol. 106, no. 1, pp. 118-124, 2005.

[48] M. N. O'Connor, I. I. Salles, A. Cvejic et al., "Functional genomics in zebrafish permits rapid characterization of novel platelet membrane proteins," Blood, vol. 113, no. 19, pp. 4754-4762, 2009.

[49] K. N. Adams, K. Takaki, L. E. Connolly et al., "Drug tolerance in replicating mycobacteria mediated by a macrophageinduced efflux mechanism," Cell, vol. 145, no. 1, pp. 39-53, 2011.

[50] E. L. Benard, A. M. van der Sar, F. Ellett, G. J. Lieschke, H. P. Spaink, and A. H. Meijer, "Infection of zebrafish embryos with intracellular bacterial pathogens," The Journal of Visualized Experiments, no. 61, article e3781, 2012.

[51] R. Carvalho, J. de Sonneville, O. W. Stockhammer et al., "A high-throughput screen for tuberculosis progression," PLoS One, vol. 6, no. 2, Article ID e16779, 2011.

[52] C. A. Loynes, J. S. Martin, A. Robertson et al., "Pivotal advance: pharmacological manipulation of inflammation resolution during spontaneously resolving tissue neutrophilia in the zebrafish," Journal of Leukocyte Biology, vol. 87, no. 2, pp. 203-212, 2010.

[53] S. L. Walker, J. Ariga, J. R. Mathias et al., "Automated reporter quantification in vivo: high-throughput screening method for reporter-based assays in zebrafish," PLoS One, vol. 7, no. 1, Article ID e29916, 2012.

[54] A. Vogt, H. Codore, B. W. Day, N. A. Hukriede, and M. Tsang, "Development of automated imaging and analysis for zebrafish chemical screens," Journal of Visualized Experiments, vol. 40, article e1900, 2010.

[55] C. A. Lessman, "The developing zebrafish (Danio rerio): avertebrate model for high-throughput screening of chemical libraries," Birth Defects Research Part C, vol. 93, no. 3, pp. 268-280, 2011.

[56] J. R. Yeh and K. M. Munson, "Zebrafish small molecule screen in reprogramming/cell fate modulation," Methods in Molecular Biology, vol. 636, pp. 317-327, 2010.

[57] J. R. J. Yeh, K. M. Munson, Y. L. Chao, Q. P. Peterson, C. A. MacRae, and R. T. Peterson, "AML1-ETO reprograms hematopoietic cell fate by downregulating scl expression," Development, vol. 135, no. 2, pp. 401-410, 2008. 
[58] F. Ellett, L. Pase, J. W. Hayman, A. Andrianopoulos, and G. J. Lieschke, "mpeg1 promoter transgenes direct macrophagelineage expression in zebrafish," Blood, vol. 117, no. 4, pp. e49-e56, 2011.

[59] S. K. Yoo, Q. Deng, P. J. Cavnar, Y. I. Wu, K. M. Hahn, and A. Huttenlocher, "Differential regulation of protrusion and polarity by $\mathrm{PI}(3) \mathrm{K}$ during neutrophil motility in live zebrafish," Developmental Cell, vol. 18, no. 2, pp. 226-236, 2010.

[60] B. Pruvot, A. Jacquel, N. Droin et al., "Leukemic cell xenograft in zebrafish embryo for investigating drug efficacy," Haematologica, vol. 96, no. 4, pp. 612-616, 2011.

[61] A. C. H. Smith, A. R. Raimondi, C. D. Salthouse et al., "Highthroughput cell transplantation establishes that tumor-initiating cells are abundant in zebrafish T-cell acute lymphoblastic leukemia," Blood, vol. 115, no. 16, pp. 3296-3303, 2010.

[62] R. M. White, A. Sessa, C. Burke et al., "Transparent adult zebrafish as a tool for in vivo transplantation analysis," Cell Stem Cell, vol. 2, no. 2, pp. 183-189, 2008.

[63] D. Traver, B. H. Paw, K. D. Poss, W. T. Penberthy, S. Lin, and L. I. Zon, "Transplantation and in vivo imaging of multilineage engraftment in zebrafish bloodless mutants," Nature Immunology, vol. 4, no. 12, pp. 1238-1246, 2003.

[64] D. Traver, A. Winzeler, H. M. Stern et al., "Effects of lethal irradiation in zebrafish and rescue by hematopoietic cell transplantation," Blood, vol. 104, no. 5, pp. 1298-1305, 2004.

[65] D. L. Stachura, O. Svoboda, R. P. Lau et al., "Clonal analysis of hematopoietic progenitor cells in the zebrafish," Blood, vol. 118, no. 5, pp. 1274-1282, 2011.

[66] V. Wittamer, J. Y. Bertrand, P. W. Gutschow, and D. Traver, "Characterization of the mononuclear phagocyte system in zebrafish,” Blood, vol. 117, no. 26, pp. 7126-7135, 2011.

[67] P. Jagadeeswaran, J. P. Sheehan, F. E. Craig, and D. Troyer, "Identification and characterization of zebrafish thrombocytes," British Journal of Haematology, vol. 107, no. 4, pp. 731-738, 1999.

[68] C. M. Bennett, J. P. Kanki, J. Rhodes et al., "Myelopoiesis in the zebrafish, Danio rerio," Blood, vol. 98, no. 3, pp. 643-651, 2001.

[69] G. J. Lieschke, A. C. Oates, M. O. Crowhurst, A. C. Ward, and J. E. Layton, "Morphologic and functional characterization of granulocytes and macrophages in embryonic and adult zebrafish," Blood, vol. 98, no. 10, pp. 3087-3096, 2001.

[70] G. Lugo-Villarino, K. M. Balla, D. L. Stachura, K. Bañuelos, M. B. F. Werneck, and D. Traver, "Identification of dendritic antigen-presenting cells in the zebrafish," Proceedings of the National Academy of Sciences of the United States of America, vol. 107, no. 36, pp. 15850-15855, 2010.

[71] C. E. Willett, A. G. Zapata, N. Hopkins, and L. A. Steiner, "Expression of zebrafish rag genes during early development identifies the thymus," Developmental Biology, vol. 182, no. 2, pp. 331-341, 1997.

[72] N. Hsia and L. I. Zon, "Transcriptional regulation of hematopoietic stem cell development in zebrafish," Experimental Hematology, vol. 33, no. 9, pp. 1007-1014, 2005.

[73] H. D. Song, X. J. Sun, M. Deng et al., "Hematopoietic gene expression profile in zebrafish kidney marrow," Proceedings of the National Academy of Sciences of the United States of America, vol. 101, no. 46, pp. 16240-16245, 2004.

[74] J. L. O. De Jong and L. I. Zon, "Use of the zebrafish system to study primitive and definitive hematopoiesis," Annual Review of Genetics, vol. 39, pp. 481-501, 2005.

[75] A. T. Chen and L. I. Zon, "Zebrafish blood stem cells," Journal of Cellular Biochemistry, vol. 108, no. 1, pp. 35-42, 2009.
[76] J. Rhodes, A. Hagen, K. Hsu et al., "Interplay of pu.1 and Gatal determines myelo-erythroid progenitor cell fate in zebrafish," Developmental Cell, vol. 8, no. 1, pp. 97-108, 2005.

[77] J. L. Galloway, R. A. Wingert, C. Thisse, B. Thisse, and L. I. Zon, "Loss of Gata1 but not Gata2 converts erythropoiesis to myelopoiesis in zebrafish embryos," Developmental Cell, vol. 8, no. 1, pp. 109-116, 2005.

[78] C. E. Burns, D. Traver, E. Mayhall, J. L. Shepard, and L. I. Zon, "Hematopoietic stem cell fate is established by the NotchRunx pathway," Genes and Development, vol. 19, no. 19, pp. 2331-2342, 2005.

[79] J. Y. Bertrand, A. D. Kim, E. P. Violette, D. L. Stachura, J. L. Cisson, and D. Traver, "Definitive hematopoiesis initiates through a committed erythromyeloid progenitor in the zebrafish embryo," Development, vol. 134, no. 23, pp. 4147-4156, 2007.

[80] K. Kissa, E. Murayama, A. Zapata et al., "Live imaging of emerging hematopoietic stem cells and early thymus colonization," Blood, vol. 111, no. 3, pp. 1147-1156, 2008.

[81] E. Murayama, K. Kissa, A. Zapata et al., "Tracing hematopoietic precursor migration to successive hematopoietic organs during zebrafish development," Immunity, vol. 25, no. 6, pp. 963-975, 2006.

[82] H. Jin, R. Sood, J. Xu et al., "Definitive hematopoietic stem/progenitor cells manifest distinct differentiation output in the zebrafish VDA and PBI," Development, vol. 136, no. 4, pp. 647-654, 2009.

[83] T. North, T. L. Gu, T. Stacy et al., "Cbfa2 is required for the formation of intra-aortic hematopoietic clusters," Development, vol. 126, no. 11, pp. 2563-2575, 1999.

[84] T. E. North, M. F. T. R. De Bruijn, T. Stacy et al., "Runx1 expression marks long-term repopulating hematopoietic stem cells in the midgestation mouse embryo," Immunity, vol. 16, no. 5, pp. 661-672, 2002.

[85] M. Gering and R. Patient, "Hedgehog signaling is required for adult blood stem cell formation in zebrafish embryos," Developmental Cell, vol. 8, no. 3, pp. 389-400, 2005.

[86] W. Goessling, T. E. North, S. Loewer et al., "Genetic Interaction of PGE2 and Wnt signaling regulates developmental specification of stem cells and regeneration," Cell, vol. 136, no. 6, pp. 1136-1147, 2009.

[87] C. E. Burns, J. L. Galloway, A. C. H. Smith et al., "A genetic screen in zebrafish defines a hierarchical network of pathways required for hematopoietic stem cell emergence," Blood, vol. 113, no. 23, pp. 5776-5782, 2009.

[88] A. Amsterdam, R. M. Nissen, Z. Sun, E. C. Swindell, S. Farrington, and N. Hopkins, "Identification of 315 genes essential for early zebrafish development," Proceedings of the National Academy of Sciences of the United States of America, vol. 101, no. 35, pp. 12792-12797, 2004.

[89] B. H. Paw, A. J. Davidson, Y. Zhou et al., "Cell-specific mitotic defect and dyserythropoiesis associated with erythroid band 3 deficiency," Nature Genetics, vol. 34, no. 1, pp. 59-64, 2003.

[90] A. Donovan, A. Brownlie, Y. Zhou et al., "Positional cloning of zebrafish ferroportin1 identifies a conserved vertebrate iron exporter," Nature, vol. 403, no. 6771, pp. 776-781, 2000.

[91] D. G. Ransom, N. Bahary, K. Niss et al., "The Zebrafish moonshine gene encodes transcriptional intermediary factor $1 \gamma$, an essential regulator of hematopoiesis," PLoS Biology, vol. 2, no. 8, article e237, 2004.

[92] J. Chen, C. Jette, J. P. Kanki, J. C. Aster, A. T. Look, and J. D. Griffin, "NOTCH1-induced T-cell leukemia in transgenic zebrafish," Leukemia, vol. 21, no. 3, pp. 462-471, 2007. 
[93] X. Le, D. M. Langenau, M. D. Keefe, J. L. Kutok, D. S. Neuberg, and L. I. Zon, "Heat shock-inducible Cre/Lox approaches to induce diverse types of tumors and hyperplasia in transgenic zebrafish," Proceedings of the National Academy of Sciences of the United States of America, vol. 104, no. 22, pp. 9410-9415, 2007.

[94] H. E. Sabaawy, M. Azuma, L. J. Embree, H. J. Tsai, M. F. Starost, and D. D. Hickstein, "TEL-AML1 transgenic zebrafish model of precursor B cell lymphoblastic leukemia," Proceedings of the National Academy of Sciences of the United States of America, vol. 103, no. 41, pp. 15166-15171, 2006.

[95] H. Feng, D. L. Stachura, R. M. White et al., "T-lymphoblastic lymphoma cells express high levels of BCL2, S1P1, and ICAM1, leading to a blockade of tumor cell intravasation," Cancer Cell, vol. 18, no. 4, pp. 353-366, 2010.

[96] A. M. Forrester, C. Grabher, E. R. Mcbride et al., "NUP98HOXA9-transgenic zebrafish develop a myeloproliferative neoplasm and provide new insight into mechanisms of myeloid leukaemogenesis," British Journal of Haematology, vol. 155, pp. 167-181, 2011.

[97] Y. Doyon, J. M. McCammon, J. C. Miller et al., "Heritable targeted gene disruption in zebrafish using designed zinc-finger nucleases," Nature Biotechnology, vol. 26, no. 6, pp. 702-708, 2008.

[98] J. E. Foley, J. R. J. Yeh, M. L. Maeder et al., "Rapid mutation of endogenous zebrafish genes using zinc finger nucleases made by oligomerized pool ENgineering (OPEN)," PLoS One, vol. 4, no. 2, Article ID e4348, 2009.

[99] X. Meng, M. B. Noyes, L. J. Zhu, N. D. Lawson, and S. A. Wolfe, "Targeted gene inactivation in zebrafish using engineered zinc-finger nucleases," Nature Biotechnology, vol. 26, no. 6, pp. 695-701, 2008.

[100] J. D. Sander, E. J. Dahlborg, M. J. Goodwin et al., "Selectionfree zinc-finger-nuclease engineering by context-dependent assembly (CoDA)," Nature Methods, vol. 8, no. 1, pp. 67-69, 2011.

[101] C. S. Williams, M. Mann, and R. N. DuBois, "The role of cyclooxygenases in inflammation, cancer, and development," Oncogene, vol. 18, no. 55, pp. 7908-7916, 1999.

[102] T. Grosser, S. Yusuff, E. Cheskis, M. A. Pack, and G. A. FitzGerald, "Developmental expression of functional cyclooxygenases in zebrafish," Proceedings of the National Academy of Sciences of the United States of America, vol. 99, no. 12, pp. 8418-8423, 2002.

[103] T. E. North, W. Goessling, M. Peeters et al., "Hematopoieticstem cell development is dependent on blood flow," Cell, vol. 137, no. 4, pp. 736-748, 2009.

[104] C. Delaney, S. Heimfeld, C. Brashem-Stein, H. Voorhies, R. L. Manger, and I. D. Bernstein, "Notch-mediated expansion of human cord blood progenitor cells capable of rapid myeloid reconstitution," Nature Medicine, vol. 16, no. 2, pp. 232-236, 2010.

[105] A. E. Boitano, J. Wang, R. Romeo et al., "Aryl hydrocarbon receptor antagonists promote the expansion of human hematopoietic stem cells," Science, vol. 329, no. 5997, pp. 1345$1348,2010$.

[106] C. C. Zhang, M. Kaba, S. Lizuka, H. Huynh, and H. F. Lodish, "Angiopoietin-like 5 and IGFBP2 stimulate ex vivo expansion of human cord blood hematopoietic stem cells as assayed by NOD/sCiD transplantation," Blood, vol. 111, no. 7, pp. 34153423, 2008.

[107] K. K. Ballen, E. J. Shpall, D. Avigan et al., "Phase I trial of parathyroid hormone to facilitate stem cell mobilization,"
Biology of Blood and Marrow Transplantation, vol. 13, no. 7, pp. 838-843, 2007.

[108] J. Hoggatt, P. Singh, J. Sampath, and L. M. Pelus, "Prostaglandin E2 enhances hematopoietic stem cell homing, survival, and proliferation," Blood, vol. 113, no. 22, pp. 54445455, 2009.

[109] H. E. Broxmeyer, S. Cooper, D. M. Hass, J. K. Hathaway, F. B. Stehman, and G. Hangoc, "Experimental basis of cord blood transplantation," Bone Marrow Transplantation, vol. 44, no. 10, pp. 627-633, 2009.

[110] W. Goessling, R. S. Allen, X. Guan et al., "Prostaglandin E2 enhances human cord blood stem cell xenotransplants and shows long-term safety in preclinical nonhuman primate transplant models," Cell Stem Cell, vol. 8, no. 4, pp. 445-458, 2011.

[111] J. M. Butler, D. J. Nolan, E. L. Vertes et al., "Endothelial cells are essential for the self-renewal and repopulation of notchdependent hematopoietic stem cells," Cell Stem Cell, vol. 6, no. 3, pp. 251-264, 2010.

[112] G. Nucifora, D. J. Birn, P. Erickson et al., "Detection of DNA rearrangements in the AML1 and ETO loci and of an AML1/ ETO fusion mRNA in patients with $\mathrm{t}(8 ; 21)$ acute myeloid leukemia," Blood, vol. 81, no. 4, pp. 883-888, 1993.

[113] B. Lutterbach, J. J. Westendorf, B. Linggi, S. Isaac, E. Seto, and S. W. Hiebert, "A mechanism of repression by acute myeloid leukemia-1, the target of multiple chromosomal translocations in acute leukemia," Journal of Biological Chemistry, vol. 275, no. 1, pp. 651-656, 2000.

[114] R. K. Hyde, Y. Kamikubo, S. Anderson et al., "Cbfb/Runx1 repression-independent blockage of differentiation and accumulation of Csf2rb-expressing cells by Cbfb-MYH11," Blood, vol. 115, no. 7, pp. 1433-1443, 2010.

[115] M. Higuchi, D. O’Brien, P. Kumaravelu, N. Lenny, E. J. Yeoh, and J. R. Downing, "Expression of a conditional AML1ETO oncogene bypasses embryonic lethality and establishes a murine model of human $\mathrm{t}(8 ; 21)$ acute myeloid leukemia," Cancer Cell, vol. 1, no. 1, pp. 63-74, 2002.

[116] J. C. Mulloy, J. Cammenga, F. J. Berguido et al., "Maintaining the self-renewal and differentiation potential of human CD34+ hematopoietic cells using a single genetic element," Blood, vol. 102, no. 13, pp. 4369-4376, 2003.

[117] J. C. Mulloy, J. Cammenga, K. L. MacKenzie, F. J. Berguido, M. A. S. Moore, and S. D. Nimer, "The AML1-ETO fusion protein promotes the expansion of human hematopoietic stem cells," Blood, vol. 99, no. 1, pp. 15-23, 2002.

[118] T. Okuda, Z. Cai, S. Yang et al., "Expression of a knockedin AML1-ETO leukemia gene inhibits the establishment of normal definitive hematopoiesis and directly generates dysplastic hematopoietic progenitors," Blood, vol. 91, no. 9, pp. 3134-3143, 1998.

[119] M. Schwieger, J. Löhler, J. Friel, M. Scheller, I. Horak, and C. Stocking, "AML1-ETO inhibits maturation of multiple lymphohematopoietic lineages and induces myeloblast transformation in synergy with ICSBP deficiency," Journal of Experimental Medicine, vol. 196, no. 9, pp. 1227-1240, 2002.

[120] M. L. Kalev-Zylinska, J. A. Horsfield, M. V. C. Flores et al., "Runx1 is required for zebrafish blood and vessel development and expression of a human RUNX-1-CBF2T1 transgene advances a model for studies of leukemogenesis," Development, vol. 129, no. 8, pp. 2015-2030, 2002.

[121] Y. Choi, K. E. Elagib, L. L. Delehanty, and A. N. Goldfarb, "Erythroid inhibition by the leukemic fusion AML1-ETO is associated with impaired acetylation of the major erythroid 
transcription factor GATA-1," Cancer Research, vol. 66, no. 6, pp. 2990-2996, 2006.

[122] T. Pabst, B. U. Mueller, N. Harakawa et al., "AML1ETO downregulates the granulocytic differentiation factor $\mathrm{C} / \mathrm{EBP} \alpha$ in $\mathrm{t}(8 ; 21)$ myeloid leukemia," Nature Medicine, vol. 7, no. 4, pp. 444-451, 2001.

[123] B. A. Hug and M. A. Lazar, "ETO interacting proteins," Oncogene, vol. 23, no. 24, pp. 4270-4274, 2004.

[124] J. Wang, Y. Saunthararajah, R. L. Redner, and J. M. Liu, "Inhibitors of histone deacetylase relieve ETO-mediated repression and induce differentiation of AML1-ETO leukemia cells," Cancer Research, vol. 59, no. 12, pp. 2766-2769, 1999.

[125] H. S. Kim, H. G. Moon, W. Han et al., "COX2 overexpression is a prognostic marker for stage III breast cancer," Breast Cancer Research and Treatment, pp. 1-9, 2011.

[126] C. E. Eberhart, R. J. Coffey, A. Radhika, F. M. Giardiello, S. Ferrenbach, and R. N. Dubois, "Up-regulation of cyclooxygenase 2 gene expression in human colorectal adenomas and adenocarcinomas," Gastroenterology, vol. 107, no. 4, pp. 1183-1188, 1994.

[127] J. Shao, C. Jung, C. Liu, and H. Sheng, "Prostaglandin E2 stimulates the $\beta$-catenin/T cell factor-dependent transcription in colon cancer," Journal of Biological Chemistry, vol. 280, no. 28, pp. 26565-26572, 2005.

[128] M. D. Castellone, H. Teramoto, B. O. Williams, K. M. Druey, and J. S. Gutkind, "Medicine: prostaglandin E2 promotes colon cancer cell growth through a Gs-axin- $\beta$-catenin signaling axis," Science, vol. 310, no. 5753, pp. 1504-1510, 2005.

[129] Y. Wang, A. V. Krivtsov, A. U. Sinha et al., "The wnt/ $\beta$-catenin pathway is required for the development of leukemia stem cells in AML," Science, vol. 327, no. 5973, pp. 1650-1653, 2010.

[130] G. Steinert, C. Oancea, J. Roos et al., "Sulindac sulfide reverses aberrant self-renewal of progenitor cells induced by the AML-associated fusion proteins PML/RAR $\alpha$ and PLZF/ rar $\alpha$, PLoS One, vol. 6, no. 7, Article ID e22540, 2011.

[131] C. M. Kasum, C. K. Blair, A. R. Folsom, and J. A. Ross, "Non-steroidal anti-inflammatory drug use and risk of adult leukemia," Cancer Epidemiology Biomarkers and Prevention, vol. 12, no. 6, pp. 534-537, 2003.

[132] J. M. Pogoda, J. Katz, R. McKean-Cowdin, P. W. Nichols, R. K. Ross, and S. Preston-Martin, "Prescription drug use and risk of acute myeloid leukemia by French-American-British subtype: results from a Los Angeles County case-control study," International Journal of Cancer, vol. 114, no. 4, pp. 634-638, 2005.

[133] G. Jeannet, M. Scheller, L. Scarpellino et al., "Long-term, multilineage hematopoiesis occurs in the combined absence of $\beta$-catenin and $\gamma$-catenin," Blood, vol. 111, no. 1, pp. 142$149,2008$.

[134] U. Koch, A. Wilson, M. Cobas, R. Kemler, H. R. MacDonald, and F. Radtke, "Simultaneous loss of $\beta$ - and $\gamma$-catenin does not perturb hematopoiesis or lymphopoiesis," Blood, vol. 111 , no. 1, pp. 160-164, 2008.

[135] M. Cobas, A. Wilson, B. Ernst et al., “ $\beta$-catenin is dispensable for hematopoiesis and lymphopoiesis," Journal of Experimental Medicine, vol. 199, no. 2, pp. 221-229, 2004.

[136] C. Zhao, J. Blum, A. Chen et al., "Loss of $\beta$-catenin impairs the renewal of normal and CML stem cells in vivo," Cancer Cell, vol. 12, no. 6, pp. 528-541, 2007.

[137] A. Redaelli, M. F. Botteman, J. M. Stephens, S. Brandt, and C. L. Pashos, "Economic burden of acute myeloid leukemia: a literature review," Cancer Treatment Reviews, vol. 30, no. 3, pp. 237-247, 2004.
[138] R. M. Stone, M. R. O’Donnell, and M. A. Sekeres, “Acute myeloid leukemia," American Society of Hematology. Education Program, pp. 98-117, 2004. 


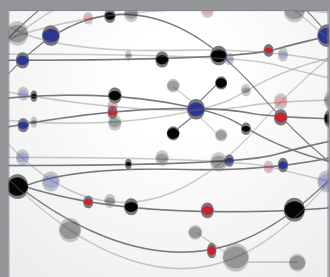

The Scientific World Journal
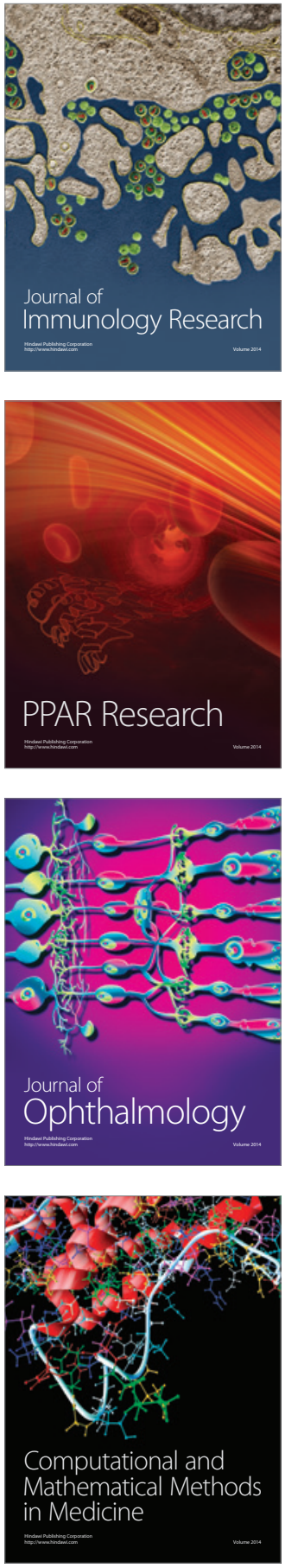

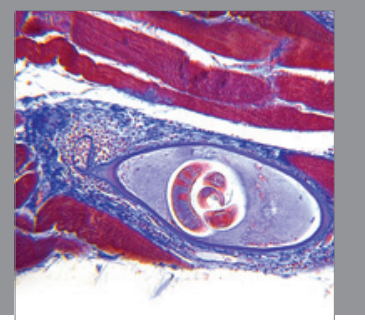

Gastroenterology

Research and Practice
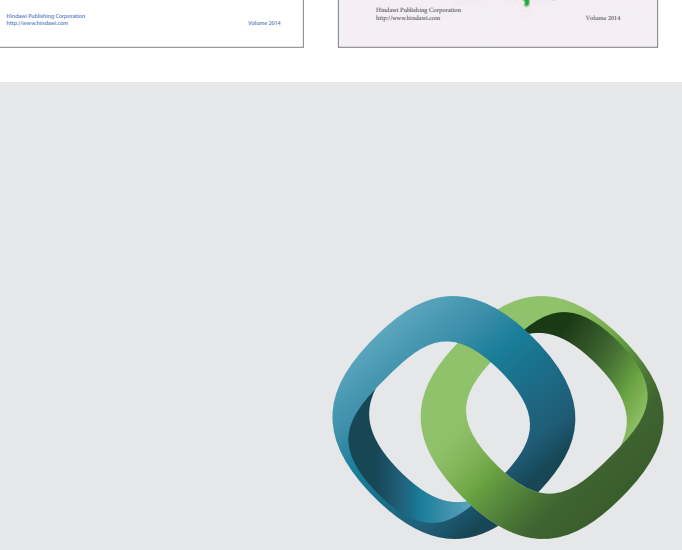

\section{Hindawi}

Submit your manuscripts at

http://www.hindawi.com
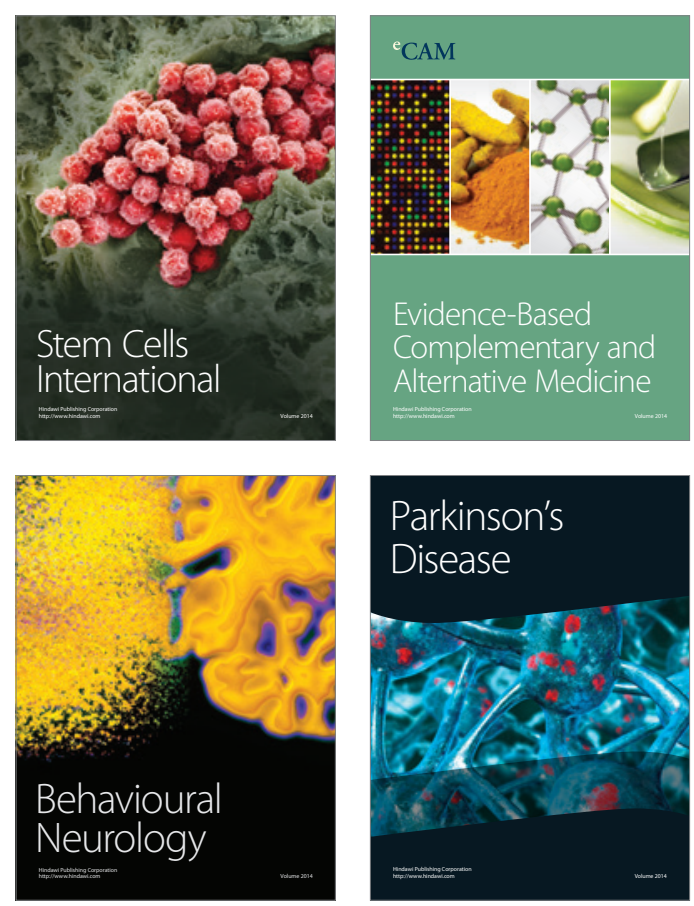

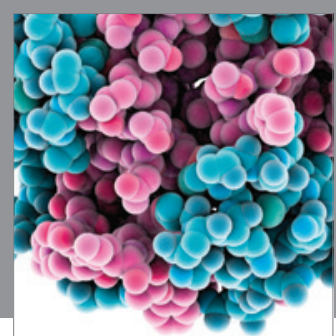

Journal of
Diabetes Research

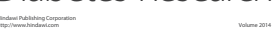

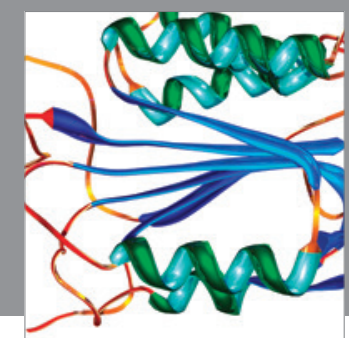

Disease Markers
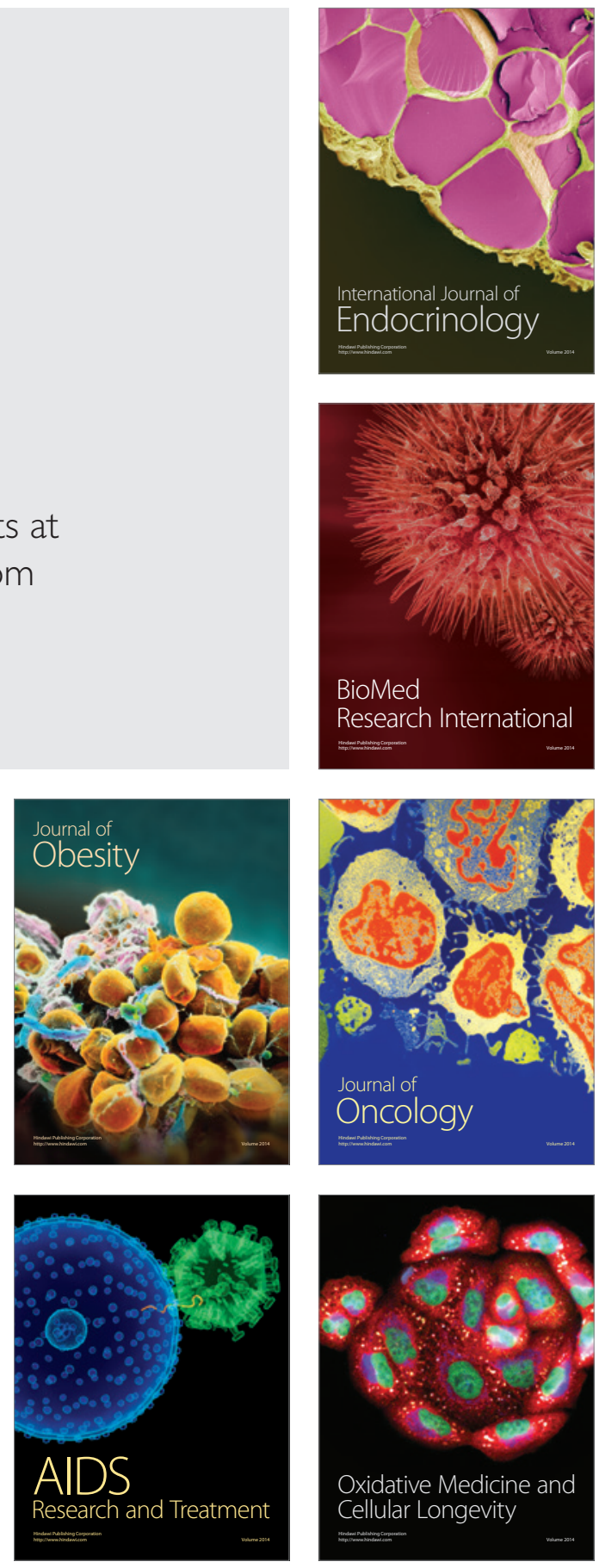